It is necessary to establish multidisciplinary data collection system of national RTA with the collaboration of Police, NCDC, and SSD, but these data must be properly coded. Reliable and accurate data guarantee developing and implementing injury prevention and control programs.

\section{DEATHS AND SERIOUS INJURIES CAUSED BY ROAD TRAFFIC CRASHES USING DATA RECORD LINKAGE IN BRAZILIAN MACRO-REGIONS}

Polyana Maria Pimenta Mandacarú, Otaliba Libânio de Morais Netọ, Luiz Arthur Franco Beniz, Fernando Rezek Rodrigues, Caio Ferro Botacin. University Federal of Goias

\subsection{6/injuryprev-2016-042156.877}

Background Low and middle income countries account for $92 \%$ of deaths from road traffic injuries (RTI) in the world. Furthermore, the mortality data completeness and reliability are poorer than high income countries. Because of that, it's necessary to qualify the databases to produce health indicators that adequately portray that situation. The data record linkage enables greater use of existing data in different sources of data. The objective was to measure the magnitude of deaths and serious injuries by using record linkage and to estimate correction factors for health and road traffic databases and in five urban areas that represent all macro regions of the Brazil.

Method Cross-Sectional study, using the road traffic victim database (VIT), Information System of Hospitalisation (SIH) and Mortality Information System (SIM), the year of 2013 for Teresina and 2012 for the remaining four cities. For the linkage procedure, the software RecLink 3 was used. The number of deaths and serious injured victims of RTI were identified. The overall global percentage of correction of the underlying cause of death and the hospitalisation diagnosis were estimated and the victim condition in the road traffic database.

Result The overall percentage of correction of the underlying cause of death for the SIM were 29.9, 11.9, 4.2, and 33.5 respectively to Belo Horizonte, Campo Grande, Curitiba and Teresina. For the city of Palmas, there was no correction. For the SIH, the percentage of correction of the hospitalisation cause were 24.4 for Belo Horizonte, 96.9 for Campo Grande, 100 for Palmas and 33 for Teresina. For the VIT, there were changes in the victim's severity classification with overall percentage of 100 for Belo Horizonte and Teresina, 48 for Campo Grande and 51 for Palmas.

Conclusion There are considerable gaps and limitations on information system that record RTI, requiring the incorporation of national standards and integration between health databases and traffic databases.

\section{SURVEILLANCE IN THE SERVICE OF SAFETY}

Rashid Jooma. Department of Surgery, Aga Khan University and Road Injury Research and Prevention Centre, Karachi, Pakistan

\subsection{6/injuryprev-2016-042156.878}

Background It has been recommended that the newly motorizing countries establish road injury surveillance to define the burden, identify high risk groups, plan intervention and monitor their impact. Despite its stated importance in the literature, very few examples of sustained surveillance systems are reported from low income countries. We present the results of an urban road injury surveillance program that has been running for the past 8 years in the emergency departments of five major hospitals in Karachi, Pakistan.

Methods We describe the process of establishing the road injury surveillance system incorporating a multi-institution research group including physicians and transportation engineers. Data was collected from 5 hospitals with details of the injury, severity scoring and information of the circumstances of the crash. Crash site visits supplemented this data and the results were disseminated to municipal authorities along with low cost engineering solutions to rectify hazards in the road network. The impact of these interventions were monitored in the surveillance.

Results In the 8 years between 2007 and 2014, 262,269 road injury victims were registered. Though $76 \%$ of the injuries were categorised as "minor", 20\% led to hospital admission and in 3\% deaths occurred. The information on location of crashes and site visits led to an extensive catalogue of road network hazards and their rectification led to demonstrated reductions in crash frequency. Data was also used for safety advocacy in groups found to be vulnerable in the surveillance, such as motorcyclists, road sweepers and school going pedestrians.

Conclusions We demonstrate that a functional road injury surveillance program can be established and effectively managed in a developing country. The data collected and analysed from the victim's perspective can be a potent tool for effecting safety education and hazard rectification.

\section{DATA MINING IN PROMOTING FLIGHT SAFETY}

Olli Sjöblom. Turku University School of Economics, Finland

\subsection{6/injuryprev-2016-042156.879}

Background The global rate of aviation accidents has recently been stabilising and the situation can now be regarded as satisfactory, but because of the growth in air traffic, the absolute number of fatal accidents per year might increase, if the flight safety will not be improved. The collection of data and reporting systems have reached their top level. The focal point in increasing the flight safety is analysis.

Methods The source of aviation safety data are those from the aviation field collected deviation and incident reports that include both structured and narrative fields. 1200 flight safety reports from a three-year period were used as test material. The narratives of these written in Finnish were processed with three text mining tools applying clustering. One is totally language independent, the other has a specific configuration for Finnish and the third was originally created for English, but encouraging results achieved with other languages, a Finnish test was undertaken, too. The totally language independent one is a Finnish prototype created in one of the Universities of Technology, the two others commercial products. The mining was carried out by performing one round with all the systems and the second with two of them in order to get more accurate mining results after refining the mining definitions.

Results It is obvious that in case events leading to lethal trends would have existed in the data, they would have been discovered and brought out. The text mining tools used were capable of extracting trends - actually recurring events - that turned out to be incidents. However, in the cases studied they did not develop into dangerous risks or accidents.

Conclusions All systems provided encouraging results, as well as proved challenges still to be won. Flight safety can be 